\title{
Os Efeitos da Privatização sobre o Desempenho Econômico e Financeiro das Empresas Privatizadas*
}

\author{
Francisco Anuatti-Neto ${ }^{* *}$ \\ Milton Barossi-Filho ${ }^{* * *}$ \\ Antonio Gledson de Carvalho ${ }^{* * * *}$ \\ Roberto Macedo ${ }^{* * * * *}$
}

Sumário: 1. Introdução; 2. O programa brasileiro de privatização; 3. Dados e variáveis; 4. Metodologia; 5. Resultados empíricos; 6 . Conclusão.

Palavras-chave: privatização; desempenho das empresas privatizadas.

Códigos JEL: L33.

Este artigo tem seu foco no efeito da privatização sobre as empresas privatizadas no Brasil. A amostra é extensiva incluindo todas as empresas do setor produtivo privatizadas desde 1991, para as quais foi possível encontrar demonstrações financeiras. Examinamos um conjunto de 15 indicadores de desempenho. Por meio de uma análise de dados em painel, foi possível capturar os efeitos da privatização sobre o desempenho das empresas privatizadas, controlando efeitos importantes como flutuações macroeconômicas, regulação, listagem em bolsa, atuação em setores tradable, participação minoritária do governo no bloco de controle e reestruturação anterior à privatização. Detectamos um aumento na lucratividade e na eficiência operacional destas empresas. A perda do suporte financeiro do estado também implica um ajuste financeiro por meio do aumento da liquidez corrente e redução do endividamento de longo

\footnotetext{
*Artigo recebido em out. 2003 e aprovado em dez. 2004. Este trabalho foi desenvolvido com o apoio financeiro da FIPE e da Rede de Centros de Pesquisa do BID-Banco Interamericano de Desenvolvimento. Agradecemos também a colaboração da Economática, Austin Assis e Fundação Getulio Vargas na cessão das bases de dados e de Renata Domingos e Alan de Genaro Dario no seu processamento. Eventuais erros ou omissões são de responsabilidade exclusiva dos autores.

** Professor da Universidade de São Paulo e pesquisador da Fundação Instituto de Pesquisas Econômicas (FIPE). E-mail: fanuatti@usp.br

*** Professor da Universidade de São Paulo e pesquisador da Fundação Instituto de Pesquisas Econômicas (FIPE). E-mail: mbarossi@fipe.com

**** Professor da Escola de Administração de Empresas de São Paulo da Fundação Getulio Vargas. E-mail: gledson@fgvsp.br

${ }^{* * * * *}$ Professor da Universidade de São Paulo, Universidade Presbiteriana Mackenzie, FAAPFundação Armando Álvares Penteado e pesquisador da FIPE. E-mail: roberto@macedo.com
} 
prazo. Os efeitos sobre investimento, produção e pagamento de dividendos e impostos são menos claros.

This article focuses on the effect of privatization on the performance of privatized enterprises in Brazil. Our sample is the most extensive possible, including all privatized companies of the productive industry since 1991 for which financial statements were available. 15 indicators of performance were examined. Through panel data analysis it was possible to capture the effects of privatization on firm's performance, controlling for important effects such as macroeconomic fluctuation, regulation, public listing, insertion in a tradable sector, minority governmental participation in the control, and merger or split before privatization. We found an increase in profitability and operational efficiency. The loss of governmental backing causes a financial restructuring through increase in current liquidity and reduction in long term indebtedness. The effects on investment, production, and payment of dividends and taxes are unclear.

\section{Introdução}

Entre 1991 e 2001, o governo brasileiro transferiu ao setor privado o controle de mais de cem empresas estatais (referidas por EEs) e participaçõ es minoritárias em várias companhias (referidas por PMEs). Estes leilões geraram US\$67,9 bilhões em receitas, mais US\$18,1 bilhões em dívidas transferidas aos compradores, constituindo um dos maiores programas de privatização do mundo. O governo também vendeu US\$6 bilhões em ações de firmas que permaneceram como EEs, obteve US $\$ 10$ bilhões em novas concessões de serviços públicos ao setor privado, e US\$1,1 bilhão por meio da venda de participações acionárias do Banco Nacional de Desenvolvimento Econômico e Social (BNDES) em empresas privadas.

Apesar das suas dimensões, o programa brasileiro de privatizações tem recebido pouca atenção da literatura acadêmica. Por exemplo, um levantamento recente dessa literatura, feito por Megginson e Netter (2001), reconhece que o programa brasileiro "deverá permanecer muito influente", devido à sua escala e ao tamanho do país. ${ }^{1}$ Contudo, esse levantamento não faz referência a nenhum estudo específico sobre o programa brasileiro de privatização.

Na literatura nacional sobre privatização e desempenho das EEs, destacamos três estudos. No primeiro, Pinheiro e Giambiagi (1997) apresentaram uma avaliação completa do desempenho das EEs federais no período 1981-94, antes da

\footnotetext{
${ }^{1}$ Megginson (2001:326).
} 
privatização. Este estudo apresenta números decepcionantes, tanto em termos de lucratividade quanto de dividendos recebidos pelo Tesouro. Ao longo de todo o período, a taxa de lucros relativamente ao patrimônio líquido foi negativa, $-2,5 \%$, em média. Além disso, de 1988 a 1994, anos para os quais os dados estavam disponíveis, os dividendos foram de apenas $0,4 \%$ do valor das ações de propriedade do governo federal.

Uma das causas para o desempenho insatisfatório foi a política salarial das EEs. Macedo (1985) realizou uma análise abrangente dos diferenciais de salários entre as empresas privadas e as EEs. Seus dados incluíam salários e outras características individuais dos trabalhadores, obtidos de formulários preenchidos anualmente pelas firmas, conforme exigência legal. ${ }^{2} \mathrm{O}$ autor comparou os salários dos trabalhadores em pares de empresas privadas e EEs, de tamanho aproximado e dentro de um mesmo setor. Depois de excluir dos diferenciais o efeito das diferenças em educação, idade, gênero e experiência, encontrou diferenças significantes em favor dos trabalhadores das EEs. ${ }^{3}$

O terceiro estudo, Pinheiro (1996), compara o desempenho de 50 EEs antes e depois da privatização, usando dados até 1994. Os dados de demonstrações financeiras foram complementados por questionários preenchidos pelas firmas a pedido do BNDES. O estudo cobriu oito variáveis: vendas líquidas, lucro líquido, patrimônio líquido, investimento, investimento fixo, número de empregados, endividamento e um índice de liquidez. Dessas variáveis, foram derivadas outras seis para medir eficiência: vendas e lucro por empregado, a taxa de retorno na forma de lucro sobre vendas e sobre patrimônio líquido, e a propensão a investir, tanto em relação às vendas como ao patrimônio. Nenhum controle foi feito para as flutuações macroeconômicas, efeitos de agências regulatórias e listagem em bolsa. A conclusão é que a privatização aumenta a produção, a eficiê ncia, a lucratividade, a propensã o a investir, reduz o emprego e melhora os indicadores financeiros das empresas. $^{4}$

\footnotetext{
${ }^{2}$ Essa base de dados é a RAIS (Relação Anual de Informações Sociais) do Ministério do Trabalho.

${ }^{3} \mathrm{~A}$ diferença líquida das características dos trabalhadores atingiu um pico de $80 \%$. Isto ocorreu quando as características dos trabalhadores foram avaliadas de acordo com os critérios do setor privado, quando medidas pelos coeficientes de regressão das características dos trabalhadores na equação de salário daquele setor.

${ }^{4}$ Mais recentemente, num seminário patrocinado pelo BNDES para comemorar o décimo aniversário do programa de privatização, Pinheiro (2000) apresentou resultados adicionais e atualizados, desta vez cobrindo 55 firmas. Sem a forma de artigo científico, a análise simplesmente comparou o desempenho das firmas antes e depois da privatização, não relacionando assim seu desempenho com aqueles das empresas privadas. Os resultados encontrados apontam um aumento nas receitas líquidas operacionais, investimento, lucro líquido, produtividade, recolhimento de
} 
A contribuição do presente artigo abrange vários aspectos: 1) baseia-se em um número maior de indicadores de desempenho, cobre um grande número de firmas, o período de análise se estende até 2001 e utiliza informações de domínio público; ${ }^{5}$ 2) a amostra inclui somente privatizações que envolveram a alienação de controle e evita o viés de seleção por incluir tanto as grandes como as pequenas empresas, vendas de participações minoritárias e majoritárias, bem como empresas listadas e não listadas; e 3) adicionalmente aos tradicionais testes de médias usados nos trabalhos citados, recorre à análise de dados em painel que permite o controle para flutuações macroeconômicas, efeitos de agências regulatórias, listagem em bolsa e outras características das empresas.

A importância dos controles não pode ser subestimada. Por exemplo, a economia brasileira sofreu várias transformações estruturais e ajustes macroeconômicos no período da análise: abertura econômica; reforma monetária; reestruturação de vários setores de serviços públicos; criação de agências regulatórias etc. A ausência de controle para estes efeitos poderia obscurecer os resultados do impacto da privatização como tal.

Os resultados obtidos neste artigo indicam que a privatização aumentou a lucratividade e a eficiência operacional das empresas. Em termos financeiros, a perda do suporte creditício governamental força as empresas a uma reestruturação por meio da elevação da liquidez corrente e redução do endividamento de longo prazo. Por outro lado, o pagamento de imposto de renda é reduzido, tendo como possível causa à amortização do ágio pago quando da aquisição do controle da empresa. Observamos também alterações em alguns resultados quando os controles (efeitos macroeconômicos e características dos setores e contratos de privatização) são introduzidos. Isto, em conjunto às significâncias estatísticas desses coeficientes, evidenciam a importância desses controles.

Este artigo está organizado da seguinte forma: a seção 2 descreve o programa brasileiro de privatização. A seção 3 descreve a amostra e as variáveis empregadas na análise empírica. A seção 4 trata das metodologias empregadas na análise empírica. Os resultados obtidos são descritos na seção 5. A seção 6 apresenta as conclusões.

impostos e uma redução no emprego. Esta, em alguns casos, foi compensada por uma expansão no emprego terceirizado.

${ }^{5}$ Os principais estudos anteriores foram produzidos por técnicos do BNDES com dados que não são de domínio público. 


\section{O Programa Brasileiro de Privatização ${ }^{6}$}

O programa brasileiro de privatização abrange três partes: (a) o Programa Nacional de Desestatização (PND), federal, iniciado em 1991; (b) programas similares no âmbito estadual, que começaram em 1996 e (c) o programa de privatização do setor de telecomunicações, a seguir referido como Telecom. Este último, também federal, começou em 1997 como um programa separado e simultâneo ao PND. Os leilões do programa Telecom, densamente concentrados em 1997 e 1998, geraram um total de US $\$ 28,8$ bilhões em receitas, mais US $\$ 2,1$ bilhões em dívidas transferidas. O PND gerou um total de US $\$ 28,2$ bilhões em receitas, mais US $\$ 9,2$ bilhões em transferências de dívida, enquanto que os programas dos estados geraram um total de US $\$ 27,9$ bilhões em receitas, mais US $\$ 6,8$ bilhões em transferências de dívidas. $^{7}$

A composição total do programa por setores mostra que a privatização do setor elétrico foi responsável por $31 \%$ do valor total dos leilões; telecomunicações, $31 \%$; aço, 8\%; mineração, $8 \%$, óleo e gás, $7 \%$; petroquímica, $7 \%$, financeiro, $6 \%$, e outros, $2 \%$. Impulsionada pelo programa Telecom, a privatização atingiu seu pico em 1997-98, período responsável por 69\% do valor total até julho de 2001. As empresas que ainda continuaram sob o controle do governo após 2001 incluem hospitais, administrações portuárias, a Empresa Brasileira de Correios, uma empresa responsável pela pesquisa agrícola, o BNDES e outras. Entre as companhias restantes, as principais estão: no setor de eletricidade, na indústria de petróleo e no setor financeiro. ${ }^{8}$

O programa progrediu pouco depois de 1998. Entre as razões está o fato de que as privatizações e outras medidas de liberalização coincidiram com um período de lento crescimento da economia, o que enfraqueceu o apoio político ao programa. Além disso, questionamento quanto à lisura de membros do governo que tentaram estimular o interesse de grupos nos leilões da Telecom provocou forte reação política, levando o Ministro das Telecomunicações a renunciar ao cargo em 1998. Ademais, caso continuasse, o programa poderia atingir áreas politicamente sensíveis, tais como o setor de geração elétrica, onde os estados são muito fortes, o setor de petróleo, onde a gigante Petrobrás ainda desperta fortes sentimentos nacionalistas, e o quase bicentenário Banco do Brasil, que desempenha

\footnotetext{
${ }^{6}$ Coube ao BNDES (a principal fonte de dados sobre o programa brasileiro de privatização como um todo) a tarefa de administrar a privatização, incluindo parte desenvolvida no âmbito estadual. Os relatórios e outros documentos usados como fonte são BNDES (1999a,b, 2001).

${ }^{7}$ Esses valores excluem concessões de serviços públicos.

${ }^{8}$ Anuatti-Neto et alii (2003) apresenta uma descrição mais completa em termos de quais empresas o governo possuía antes do programa e quais foram privatizadas.
} 
um papel muito importante no financiamento agrícola e, assim, conta com forte apoio político.

\section{Dados e Variáveis}

\subsection{A amostra}

A amostra consiste de 102 empresas do setor produtivo privatizadas e um grupo de controle de empresas listadas em bolsa formado por 20 empresas estatais e 158 empresas privadas. A fonte dos dados é os relatórios financeiros anuais (balanços patrimoniais, demonstrações de resultados e fluxos de caixa) ${ }^{9} \mathrm{O}$ período de análise compreende os anos de 1987 a 2000. A análise desenvolvida em termos de taxas ou quocientes de variáveis minimiza as possíveis distorções oriundas das elevadas taxas de inflação que prevaleceram entre 1986 a 1994. Nos casos em que o indicador de desempenho é um valor nominal, este foi convertido em dólares.

Os relatórios financeiros foram obtidos a partir de três fontes: duas firmas de consultoria (Economática e Austin Assis) e da Fundação Getúlio Vargas. As privatizações no setor financeiro foram excluídas da amostra, uma vez que este setor apresenta padrões diferenciados. O foco da análise é a venda de pacotes de controle, tanto de natureza majoritária como minoritária. ${ }^{10}$

A tabela 1 descreve a amostra e sua cobertura. A amostra contém 102 empresas de um total de 162 empresas privatizadas. No entanto o número de empresas não é um indicador muito preciso da abrangência da amostra porque várias das antigas EEs foram vendidas como um bloco e ao comprador de uma holding operacional foi dado também o controle de suas subsidiárias. No caso do setor Telecom, por exemplo, cinco blocos amalgamados dos leilões de privatização cobriram in totum as telefonias locais fixa e móvel, de longa distância e segmentos internacionais reestruturados. Assim, recorremos ao conceito de contrato de privatização para descrever a representatividade da amostra. Desta maneira, o conjunto de companhias da amostra representa 66 contratos de privatização, correspondendo a 102 firmas. A nossa amostra cobre 64\% (66 de um total de 103) dos pacotes de controle, 69\% (102 de um total de 147) das firmas incluídas na privatização e $94 \%$ (US\$ 72 bi de um total de US\$ 76,8 bi) do valor total dos leilões de empresas não-financeiras (uma listagem de todas as empresas privatizadas no país

\footnotetext{
${ }^{9}$ Os padrões e procedimentos brasileiros de contabilidade, como estabelecidos pela lei e agências reguladoras, permaneceram os mesmos por todo o período, facilitando assim a análise.

${ }^{10}$ Os casos em que o BNDES vendeu participações acionárias da sua própria carteira como banco de investimento também foram excluídos.
} 
encontra-se no Apêndice A). O fato do número de companhias nos testes de média e mediana ser menor que o total da amostra é explicado pela metodologia adotada que é descrita na próxima seção.

Tabela 1

Descrição e cobertura da amostra

\begin{tabular}{|c|c|c|c|c|}
\hline & $\begin{array}{l}\text { Tipo de } \\
\text { empresa }\end{array}$ & $\begin{array}{l}\text { Número de } \\
\text { contratos }\end{array}$ & $\begin{array}{l}\text { Número de } \\
\text { companhias }\end{array}$ & $\begin{array}{l}\text { Leilões: receitas em } \\
\text { US\$milhões* }\end{array}$ \\
\hline \multirow{5}{*}{$\begin{array}{c}\text { Programa de } \\
\text { privatização } \\
(1991-2000)\end{array}$} & Setor financeiro & 9 & 9 & $5.112,30$ \\
\hline & Vendas minoritárias em EEs & 6 & 6 & $6.164,10$ \\
\hline & Participações do BNDES & & & $1.146,00$ \\
\hline & Vendas de pacotes de controle & 103 & 147 & $76.878,20$ \\
\hline & Total & 118 & 162 & $89.439,20$ \\
\hline \multirow[t]{3}{*}{ Amostra total** } & Controle minoritário & 16 & 16 & $1.299,20$ \\
\hline & Controle majoritário & 50 & 86 & $70.709,80$ \\
\hline & Total & 66 & 102 & $72.009,00$ \\
\hline \multicolumn{5}{|l|}{$\begin{array}{l}\text { Amostra para } \\
\text { testes de média }\end{array}$} \\
\hline \multirow{3}{*}{$\begin{array}{c}\text { Amostra para } \\
\text { análise em painel }\end{array}$} & Empresas Privatizadas & & 102 & $72.009,00$ \\
\hline & Usadas para controle & Estatais & 20 & \\
\hline & de efeitos macroeconômico & Privadas & 158 & \\
\hline
\end{tabular}

*Inclui dívidas transferidas (US $\$ 17,8$ bilhões), ações ofertadas a empregados no programa Telecom (US $\$ 0,3$ bilhão) e exclui concessões de novos serviços públicos (US $\$ 7,7$ bilhões).

**Inclui somente vendas de pacotes de controle.

\subsection{As variáveis}

Os indicadores de desempenho utilizados - listados nas tabelas 2 e 3 - são essencialmente os mesmos quinze usados em La Porta e López-de Silanes (1999). Estes são compostos por cinco indicadores de lucratividade: razão entre receita operacional e ativo imobilizado (variável $\mathrm{RO} / \mathrm{IMOB}$ ), resultado operacional e receita líquida (margem operacional), lucro líquido e receita líquida (margem líquida), lucro líquido e ativo total (variável ROA) e lucro líquido e patrimônio líquido (variável ROE); dois indicadores de eficiência operacional: logaritmo da razão entre receita líquida e ativo imobilizado (variável RL/IMOB), e a razão entre custos operacionais e receita líquida (variável $\mathrm{CO} / \mathrm{RL}$ ); três indicadores de investimento: logaritmo do ativo imobilizado (variável logIMOB) e as razões ente receita investimentos e receita líquida (variável I/RL) e investimento e ativo imobilizado (variável I/IMOB); um indicador de produto: o logaritmo da receita líquida (variável $\log \mathrm{RL})$; um indicador representativo do pagamento de dividendos: a razão entre os dividendos e o lucro líquido (variável payout, do inglês); dois indicadores financeiros: razões entre ativo e passivo correntes (variável LCOR) e dívida de longo 
prazo e patrimônio líquido (variável DLP/PL); e um indicador de pagamentos de impostos: razão entre impostos líquidos e receitas líquidas (variável IL/RL).

Na análise econométrica, para captar o efeito da privatização, usamos a variável PRIVATIZAÇÃO, uma variável dummy que assume o valor zero para os anos anteriores a privatização e um para os anos subseqüentes. Definimos também um conjunto de variáveis com o objetivo de controlar outros fatores que possam afetar o desempenho, quais sejam: variável TRADABLE, uma dummy que assume o valor um, se a companhia pertence ao setor de bens comercializáveis e zero do contrário; variável REGULAÇÃO, uma dummy que assume o valor um, se o preço do produto da firma é regulado pelo governo e zero do contrário; variável REESTRUTURAÇÃO, uma dummy que assume o valor um, se a companhia passou por uma fusão ou cisão antes de ser privatizada e zero do contrário; variável MINORITÁRIO, uma dummy que assume o valor um, se o governo possuía somente uma participação minoritária na fase de pré-privatização e zero do contrário; e variável LISTADA, uma dummy que assume o valor um, se a empresa privatizada foi listada na Bolsa de Valores de São Paulo e zero do contrário. Infelizmente, em decorrência do número reduzido de empresas que poderiam fazer parte do grupo de controle, não foi possível definir nenhum controle para o setor de atividade da empresa. Finalmente, para as variáveis receita líquida e imobilizado, cujo valor pode ser muito afetado por variações cambiais, incluímos como controle uma variável denominada por CÂMBIO, uma dummy que assume valor zero antes de 1999 e um para os anos subseqüentes.

Tabela 2

Descrição das Variáveis Primitivas

\begin{tabular}{lcl}
\hline \multicolumn{1}{c}{ Variável } & Símbolo & \multicolumn{1}{c}{ Descrição } \\
\hline Resultado operacional & RO & $\begin{array}{l}\text { Vendas, menos gastos operacionais, menos } \\
\text { custo de vendas e menos depreciação }\end{array}$ \\
\hline Receita líquida & RL & Vendas, menos impostos indiretos e devoluções \\
\hline Imobilizado & IMOB & Ativo imobilizado \\
\hline Lucro Líquido & LL & $\begin{array}{l}\text { Resultado operacional, menos gastos de juros } \\
\text { e impostos líquidos }\end{array}$ \\
\hline Investimentos & I & Variação do ativo imobilizado \\
\hline Impostos líquidos & IL & $\begin{array}{l}\text { Impostos de renda pagos livres de subsídios } \\
\text { diretos ou créditos fiscais recebidos durante o } \\
\text { ano fiscal }\end{array}$ \\
\hline
\end{tabular}


Tabela 3

Indicadores de desempenho*

\begin{tabular}{lcl}
\hline \multicolumn{1}{c}{ Critério } & Variável & \multicolumn{1}{c}{ Descrição } \\
\hline & Margem Operacional & Razão entre receita operacional e receita líquida \\
Lucratividade & RO/IMOB & Razão entre receita operacional e ativo imobilizado \\
& Margem Líquida & Razão entre lucro líquido e receita líquida \\
& ROA & Razão entre lucro líquido e ativo total \\
& Razão entre lucro líquido e patrimônio líquido \\
\hline Eficiência & RO/RL & Logaritmo da razão ente vendas e ativo imobilizado \\
operacional & Rog IMOB & Logaritmo do ativo imobilizado \\
\hline Investimento & I/RL & Razão entre investimentos e receita líquida \\
& I/IMOB & Razão entre investimentos e ativo imobilizado \\
\hline Produção & Log RL & Logaritmo da receita líquida \\
\hline Dividendos & Payout & Razão entre dividendos e lucro líquido (payout) \\
\hline Financeiro & LCOR & Razão ente ativo corrente e passivo corrente \\
& DLP/PL & Razão entre dívida de longo prazo e patrimônio líquido \\
\hline Impostos & IL/RL & Razão entre impostos e receita líquida \\
\hline *As variáveis primitivas estão descritas & na tabela 2.
\end{tabular}

\section{Metodologia}

Duas abordagens distintas foram adotadas para examinar os efeitos da privatização sobre o desempenho das empresas: os testes de média e mediana e a análise econométrica com dados em painel. A seguir discutimos cada um destes procedimentos.

\subsection{Testes de média e mediana}

Os testes de média e mediana, para captar os efeitos da privatização, são uma comparação entre as médias e as medianas dos dois anos anteriores à privatização com as observadas nos dois anos seguintes à privatização. ${ }^{11}$ Durante o período em que ocorreu a privatização, a economia brasileira passou por ciclos. Assim, mudanças no desempenho podem refletir movimentos cíclicos da economia e não os efeitos da privatização. Para contornar esse problema, usamos como controle um grupo de companhias de capital aberto. Assim, o desempenho das empresas privatizadas foi ajustado por meio da diferença entre o valor do indicador para a empresa privatizada e a média do indicador para o grupo de controle. Este procedimento

\footnotetext{
${ }^{11}$ Este procedimento difere daquele de La Porta e López-de Silanes (1999) que utilizava um ano fixo para o período pós-privatização. No caso mexicano, a privatização foi fortemente concentrada em uns poucos anos. No Brasil, foi estendida ao longo de mais de uma década. Portanto, um ano fixo para comparação seria inadequado.
} 
é similar ao de La Porta e López-de Silanes (1999) que adotaram mudanças de desempenho ajustadas setorialmente para a amostra de firmas privatizadas. ${ }^{12} \mathrm{O}$ Apêndice B detalha estes procedimentos.

\subsection{Análise econométrica}

A análise envolvendo comparações de médias e medianas tem a virtude de ser parcimoniosa e intuitiva. O ajuste dos valores originais das médias e medianas por meio de um grupo de controle elimina uma possível correlação espúria causada por efeitos macroeconômicos. No entanto, outras características das empresas privatizadas poderiam estar causando uma mudança no desempenho destas empresas sem que isto estivesse diretamente associado ao processo de privatização. Para controlar o efeito destes outros possíveis determinantes do desempenho das empresas privatizadas, recorremos à análise econométrica. O modelo empírico utilizado está definido no arcabouço de dados em painel e é representado pela seguinte equação:

$$
I P_{i t}=\alpha+\varphi I P_{i(t-1)}+\gamma \text { Privatização } \beta X_{i t}+\delta M L_{t}+e_{i t}
$$

onde $I P_{i t}$ é o indicador de desempenho (descritos na tabela 3). O efeito da privatização é captado pela variável PRIVATIZAÇÃO $X_{i t}$ é um vetor $(\mathrm{TxN})$ que contém as variáveis de controle (TRADABLE, REGULAÇÃ̃, REESTRUTURAÇÃO, MINORITÁRIO, CÂMBIO e LISTADA). Para captar o efeito dos ciclos macroeconômicos, incluímos a variável $M L_{t}$, a média observada no ano $t$ para um grupo de empresas listadas que formam o grupo de controle. O termo $I P_{i(t-1)}$, que é valor do indicador de desempenho defasado em um período é inserido no modelo com o objetivo de captar um elemento de persistência. No entanto, o valor e a significância estatística do parâmetro estimado referente a esta variável não é relevante na análise.

Devido à natureza dinâmica do painel, as estimações foram feitas usando o método de Arellano e Bond (1991), implementado pelo pacote econométrico Stata.

\footnotetext{
${ }^{12}$ Não pudemos fazer o controle por setor industrial, porque algumas das empresas privatizadas não têm um competidor correspondente no setor privado. Este é o caso, por exemplo, da CVRD (Companhia Vale do Rio Doce), uma importante companhia de mineração, as Telecoms e muitas companhias do setor de energia.
} 


\section{Resultados Empíricos}

Os resultados empíricos dos efeitos da privatização sobre o desempenho das empresas estão reportados nas tabelas 4 a 7 . As tabelas 4 e 5 apresentam os resultados dos testes de média e mediana sem e com controle para efeitos agregados, respectivamente. As tabelas 6 e 7 apresentam as estimativas dos coeficientes obtidas a partir de modelos de dados em painel. É conveniente observar que a mostra se altera de acordo com o método e critério de desempenho analisado. Isto está relacionado à disponibilidade de informação e, em parte pode explicar eventuais discrepâncias dos resultados entre diferentes métodos. Finalmente, a nossa apresentação dos resultados terá por base a análise econométrica. A comparação com os resultados da análise de média tem o efeito de ressaltar a importância dos controles.

Inicialmente observamos a importância do controle para os movimentos macroeconômicos. Isto fica bem evidenciado pela comparação entre os resultados das tabelas 4 e 5: os indicadores de margem operacional e de IL/IR tem seus sinais alterados, bem como as respectivas significâncias estatísticas, enquanto que ROE, CO/RL e logIMOB sofrem alterações apenas quanto às respectivas significâncias estatísticas. A importância do controle macroeconômico fica reforçada pelo sinal positivo e significância estatística em $1 \%$ da variável ML (GRUPO DE CONTROLE) na análise econométrica.

Em geral, os resultados indicam um crescimento da lucratividade das empresas privatizadas. Neste quesito, todos os coeficientes associados à variável PRIVATIZAÇÃO são positivos. Para os indicadores margem operacional, ROA e ROE os coeficientes são estatisticamente significantes em 1\% (os coeficientes para margem líquida e RO/IMOB não apresentam significância estatística). Nos testes de média, o único indicador com variação negativa e estatisticamente significante é a margem líquida (tabela 5). Os indicadores OI/IMOB e ROE apresentam parâmetros estimados positivos e estatisticamente significantes. Os controles para bens tradable, regulação e listagem em bolsa mostram-se estatisticamente significativos para explicar a lucratividade das empresas. Isto é importante para entender as discrepâncias com os testes de média que não controlam os efeitos destes fatores.

Os resultados claramente indicam uma melhora na eficiência operacional das empresas privatizadas. Nas duas abordagens observamos um aumento na razão entre a receita líquida e o imobilizado (RL/IMOB) e uma redução na razão entre custos operacionais e receita líquida $(\mathrm{CO} / \mathrm{RL})$. No caso da variável RL/IMOB todas as estatísticas são positivas e significativas, sugerindo que as firmas privatizadas tornaram-se mais eficientes no uso de seus ativos. Com relação à variável 
$\mathrm{CO} / \mathrm{RL}$, todas as estatísticas apresentam um sinal negativo. Apenas no teste de média com controle para efeitos macroeconômicos (tabela 5), a diferença entre as médias e medianas não se mostram estatisticamente significantes. Da análise de regressão (tabela 6), em que os coeficientes apresentam significância estatística em nível de $1 \%$, observa-se um aumento de $7 \%$ na razão RL/IMOB e uma redução de $1,5 \%$ para $\mathrm{CO} / \mathrm{RL}$.

Aparentemente, a privatização teve um impacto negativo sobre investimento em ativos imobilizados. Todos os métodos indicam uma redução estatisticamente significativa do ativo imobilizado $(\log I M O B)$ e da razão entre ativo imobilizado e receita líquida (IMOB/RL). Estes resultados parecem consistentes com o aumento na eficiência operacional registrada anteriormente. Contudo, quando consideramos a taxa de investimento (I/IMOB), a análise de regressão (tabela 7) indica um aumento da taxa de investimento (no entanto, sobre uma base menor). Novamente, a diferença entre os testes de média e a análise econométrica pode ser explicada pela introdução de controles adicionais nesta última.

$\mathrm{O}$ coeficiente associado à variável PRIVATIZAÇÃO na regressão de receita líquida é positivo e estatisticamente significante (tabela 7). No entanto devemos ser cuidadosos em concluir que isto representa um aumento na produção. Isto pode refletir também um aumento do preço do produto. O aumento da receita líquida, combinado com uma redução do ativo imobilizado permite uma melhor compreensão do aumento da eficiência operacional (RL/IMOB).

Com relação ao pagamento de dividendos (payout), nenhuma evidência conclusiva foi obtida. Nos testes de média e mediana (tabelas 4 e 5), o sinal do coeficiente é consistentemente negativo, embora nunca significativo. Devido à escassez de informação não foi possível sequer implementar a análise de regressão, uma vez que o registro sobre pagamento de dividendos estava disponível apenas para uma amostra de 45 empresas listadas em bolsa.

Um quadro claro aparece com os indicadores da estrutura financeira. Tanto os testes de média e mediana, como a análise econométrica mostram um aumento na liquidez corrente (LCOR). As estatísticas para a diferença na média e mediana, bem como o coeficiente associado à variável PRIVATIZAÇÃO são todos positivos e estatisticamente significativos. 
O efeito da privatização sobre endividamento de longo prazo (razão entre dívida de longo prazo e patrimônio líquido, DLP/PL), também parece claro. Tanto os testes de média e mediana com ajuste para variações macroeconômicas (tabela 5), quanto à análise de regressão (tabela 7) indicam uma redução estatisticamente significativa do endividamento de longo prazo. Em termos absolutos - sem ajuste para flutuações macroeconômicas - há um aumento do endividamento de longo prazo após a privatização (tabela 5). No entanto, este aumento absoluto pode estar relacionado à desvalorização cambial de 1999 que elevou consideravelmente o endividamento das empresas com passivos denominados em dólares.

Esses resultados sobre estrutura financeira são similares àqueles registrados por La Porta e López-de Silanes (1999). Após a privatização, as empresas perdem seu status de devedores garantidos pelo governo. Sem o apoio do governo, estas empresas são forçadas a ajustar sua estrutura financeira, reduzindo o nível de endividamento (DLP/PL) e aumentando a liquidez corrente.

Finalmente, nossos resultados indicam uma clara queda da razão entre imposto de renda e receita líquida (IL/RL). Em todas as análises os coeficientes são negativos e estatisticamente significativos. Há duas explicações para esse resultado. O imposto devido é apurado como a diferença entre os tributos calculados e as deduções permitidas. Como estas últimas não constituem subsídios explícitos, é conveniente descrevê-las detalhadamente, para interpretar os resultados com maior precisão.

Três categorias gerais de deduções se aplicam: incentivos fiscais, compensação para perdas prévias e créditos tributários. As perdas incorridas em um ano podem ser deduzidas do imposto de renda ao longo de vários anos. Em particular, as companhias altamente endividadas em dólares foram afetadas pela desvalorização do real no início de 1999. Perdas deste tipo foram responsáveis também por uma queda nos impostos, mesmo para o grupo de controle, em 2000.

Para os créditos tributários é importante o ágio pago nos leilões e efeitos patrimoniais decorrentes de incorporações e aquisições. A lei societária brasileira prevê ajustes para esses casos. À companhia que assume controle, é permitida a constituição de uma conta de reserva correspondente ao ágio que pode ser amortizada sobre um período de cinco a dez anos. Este benefício atinge fusões e aquisições em geral. Todo o setor privado em reestruturação e as companhias privatizadas foram beneficiários destes descontos. Portanto, há uma explicação razoável para o resultado obtido, ou seja, os pagamentos de impostos líquidos com relação às vendas diminuíram após a privatização.

Em resumo, os resultados desta seção sustentam a visão de que a privatização melhorou o desempenho das empresas que passaram pelo processo. 
Tabela 4

Efeitos da privatização sobre o desempenho das empresas privatizadas

\begin{tabular}{|c|c|c|c|c|c|}
\hline \multicolumn{6}{|c|}{$\begin{array}{c}\text { Testes de média e mediana } s e m \text { ajustamento } \\
\text { para flutuações macroeconômicas }\end{array}$} \\
\hline \multicolumn{6}{|c|}{$\begin{array}{c}\text { Comparação entre a média e a mediana dos dois anos anteriores } \\
\text { com as observadas nos dois anos seguintes à privatização. } \\
\text { A média é reportada na primeira linha e a mediana na segunda. } \\
\text { O teste para a diferença de médias é o Wilcoxon Signed Rank, } \\
\text { enquanto que o teste para diferença de medianas é o } \\
\text { Rank Sum Test }\end{array}$} \\
\hline \multirow{2}{*}{ Critério } & \multirow{2}{*}{ Indicador } & \multirow[b]{2}{*}{$N$} & \multicolumn{2}{|c|}{ Média e mediana } & \multirow[b]{2}{*}{ Teste $Z^{\S}$} \\
\hline & & & Antes & Depois & \\
\hline \multirow{10}{*}{ Lucratividade } & Margem & 66 & 0.037 & 0.042 & 0.536 \\
\hline & operacional & & 0.072 & 0.108 & 0.523 \\
\hline & LO/IMOB & 67 & 0.092 & 0.141 & $3.556^{*}$ \\
\hline & & & 0.035 & 0.107 & $3.566^{*}$ \\
\hline & Margem & 65 & 0.000 & -0.008 & -0.595 \\
\hline & líquida & & 0.034 & 0.039 & 0.677 \\
\hline & ROA & 70 & -0.860 & 0.008 & 0.291 \\
\hline & & & 0.014 & 0.011 & -1.287 \\
\hline & ROE & 70 & -1.152 & 0.046 & 0.662 \\
\hline & & & 0.019 & 0.039 & 0.862 \\
\hline \multirow{6}{*}{$\begin{array}{l}\text { Eficiência } \\
\text { operacional }\end{array}$} & Log RL/IMOB & 63 & -0.273 & -0.006 & $5.520^{*}$ \\
\hline & & & -0.201 & 0.009 & $5.492^{*}$ \\
\hline & $\mathrm{CO} / \mathrm{RL}$ & 58 & 0.375 & 0.251 & $-2.631^{*}$ \\
\hline & & & 0.200 & 0.196 & $-2.917^{*}$ \\
\hline & Log IMOB & 67 & 6.001 & 5.946 & $-1.981^{* * *}$ \\
\hline & & & 5.891 & 5.813 & $-1.983^{* * *}$ \\
\hline \multirow[t]{4}{*}{ Investimento } & $\mathrm{I} / \mathrm{RL}$ & 54 & 0.295 & -0.032 & $-2.550^{* *}$ \\
\hline & & & 0.158 & 0.093 & $-2.476^{* *}$ \\
\hline & I/IMOB & 57 & 0.115 & 0.094 & -1.202 \\
\hline & & & 0.101 & 0.104 & 0.202 \\
\hline \multirow[t]{2}{*}{ Produção } & $\log \mathrm{RL}$ & 63 & 5.644 & 5.876 & $4.335^{* *}$ \\
\hline & & & 5.403 & 5.643 & $4.301^{* *}$ \\
\hline \multirow[t]{2}{*}{ Dividendos } & Payout & 45 & 71.40 & 55.99 & -0.089 \\
\hline & & & 30.78 & 48.66 & 0.166 \\
\hline \multirow[t]{4}{*}{ Financeiro } & LCOR & 70 & 0.847 & 1.009 & $2.755^{*}$ \\
\hline & & & 0.745 & 0.866 & $3.089^{*}$ \\
\hline & $\mathrm{DLP} / \mathrm{PL}$ & 63 & 0.636 & 0.701 & $2.506^{* *}$ \\
\hline & & & 0.181 & 0.269 & $2.506^{* *}$ \\
\hline \multirow[t]{2}{*}{ Impostos } & IL/RL & 65 & 0.024 & -0.010 & $-3.834^{*}$ \\
\hline & & & 0.017 & 0.007 & $-3.343^{*}$ \\
\hline
\end{tabular}

* Significante em $10 \%$.

** Significante em $5 \%$.

$* * *$ Significante em $1 \%$. 
Tabela 5

Efeitos da privatização sobre o desempenho das empresas privatizadas

\begin{tabular}{|c|c|c|c|c|c|}
\hline \multicolumn{6}{|c|}{$\begin{array}{c}\text { Testes de média e mediana com ajustamento } \\
\text { para flutuações macroeconômicas }\end{array}$} \\
\hline \multicolumn{6}{|c|}{$\begin{array}{c}\text { Comparação entre a média e a mediana dos dois anos anteriores } \\
\text { com as observadas nos dois anos seguintes à privatização. } \\
\text { A média é reportada na primeira linha e a mediana na segunda. } \\
\text { O teste para a diferença de médias é o Wilcoxon Signed Rank, } \\
\text { enquanto que o teste para diferença de medianas é o } \\
\text { Rank Sum Test }\end{array}$} \\
\hline \multirow[t]{2}{*}{ Critério } & \multirow[t]{2}{*}{ Indicador } & \multirow[b]{2}{*}{$N$} & \multicolumn{2}{|c|}{ Média e mediana } & \multirow[b]{2}{*}{ Teste $Z^{\S}$} \\
\hline & & & Antes & Depois & \\
\hline \multirow{10}{*}{ Lucratividade } & Margem & 66 & 0.097 & -0.430 & $-2.944^{*}$ \\
\hline & operacional & & 0.084 & 0.019 & $-2.944^{*}$ \\
\hline & $\mathrm{LO} / \mathrm{IMOB}$ & 67 & -0.092 & 0.141 & $3.556^{*}$ \\
\hline & & & 0.005 & 0.222 & $5.713^{*}$ \\
\hline & Margem & 65 & -0.004 & -0.105 & -1.476 \\
\hline & líquida & & 0.020 & 0.012 & -1.534 \\
\hline & $\mathrm{ROA}$ & 70 & -0.870 & -0.014 & 0.824 \\
\hline & & & 0.003 & -0.012 & -1.369 \\
\hline & $\mathrm{ROE}$ & 70 & -1.194 & 0.025 & $1.768^{* * *}$ \\
\hline & & & -0.030 & 0.021 & $1.698^{* * *}$ \\
\hline \multirow{6}{*}{$\begin{array}{l}\text { Eficiência } \\
\text { operacional }\end{array}$} & Log RL/IMOB & 63 & -0.548 & -0.298 & $3.980^{* *}$ \\
\hline & & & -0.522 & -0.218 & $3.876^{* *}$ \\
\hline & $\mathrm{CO} / \mathrm{RL}$ & 58 & 0.174 & 0.065 & $-1.837^{*}$ \\
\hline & & & 0.014 & 0.021 & -0.809 \\
\hline & Log IMOB & 67 & 1.445 & 1.002 & -1.286 \\
\hline & & & 0.955 & 0.871 & -1.370 \\
\hline \multirow[t]{4}{*}{ Investimento } & $\mathrm{I} / \mathrm{RL}$ & 54 & 0.223 & -0.058 & $-1.887^{* *}$ \\
\hline & & & 0.117 & 0.066 & $-1.795^{* * *}$ \\
\hline & I/IMOB & 57 & 0.038 & 0.024 & -0.774 \\
\hline & & & 0.026 & 0.039 & 0.264 \\
\hline \multirow[t]{2}{*}{ Produção } & $\log \mathrm{RL}$ & 63 & 0.774 & 0.901 & $3.306^{* * *}$ \\
\hline & & & 0.274 & 0.457 & $3.598^{* * *}$ \\
\hline \multirow[t]{2}{*}{ Dividendos } & Payout & 45 & 0.309 & -0.263 & -0.229 \\
\hline & & & -28.62 & -5.805 & 0.299 \\
\hline \multirow[t]{4}{*}{ Financeiro } & LCOR & 70 & -0.510 & -0.250 & $3.238^{*}$ \\
\hline & & & -0.605 & -0.250 & $3.768^{*}$ \\
\hline & $\mathrm{DLP} / \mathrm{PL}$ & 63 & 0.254 & 0.108 & -0.210 \\
\hline & & & -0.142 & -0.325 & -0.021 \\
\hline \multirow[t]{2}{*}{ Impostos } & $\mathrm{IL} / \mathrm{RL}$ & 65 & 0.018 & -0.014 & $-3.578^{*}$ \\
\hline & & & 0.005 & 0.003 & $-3.575^{*}$ \\
\hline
\end{tabular}

* Significante em $10 \%$.

** Significante em $5 \%$.

*** Significante em $1 \%$. 
Tabela 6

Efeitos da privatização sobre o desempenho das empresas privatizadas

Análise econômica em painel

Critérios: Lucratividade e Eficiência operacional

Teste empírico do modelo $I P_{i t}=\alpha+\varphi I P_{i(t-1)}+\gamma$ PRIVATIZAÇÃO $+\beta X_{i t}+\delta M L_{t}+e_{i t}$ onde: $I P_{i t}$ é um indicador de performance e $I P_{i(t-1)}$ é o valor do indicador defasado em um período. O efeito da privatização é captado pela variável PRIVATIZAÇÃO. $X_{i t}$ é um vetor $(T x N)$ que contém as variáveis de controle(TRADABLE, REGULAÇÃO,

REESTRUTURAÇÃO, MINORITÁRIO, CÂMBIO e LISTADA). A variável $M L_{t}$, é a média observada no ano $t$ para um grupo de empresas listadas que formam o grupo de controle. Os estimadores foram obtidos pelo método de Arellano e Bond (1991), implementado pelo pacote econométrico Stata.

\begin{tabular}{|c|c|c|c|c|c|c|c|}
\hline \multirow[b]{2}{*}{ Variáveis } & \multicolumn{5}{|c|}{ Lucratividade } & \multicolumn{2}{|c|}{$\begin{array}{c}\text { Eficiência } \\
\text { operacional }\end{array}$} \\
\hline & $\begin{array}{c}\text { Margem } \\
\text { operacional }\end{array}$ & LO/IMOB & $\begin{array}{l}\text { Margem } \\
\text { líquida }\end{array}$ & $\mathrm{ROA}$ & $\mathrm{ROE}$ & $\begin{array}{c}\mathrm{Log} \\
\mathrm{RL} / \mathrm{IMOB}\end{array}$ & $\mathrm{CO} / \mathrm{RL}$ \\
\hline \multirow[t]{2}{*}{ Privatização } & $0.056^{* * *}$ & 0.033 & 0.003 & $0.016^{* * *}$ & $0.062^{* * *}$ & $0.070^{* * *}$ & $-0.015^{* * *}$ \\
\hline & 0.008 & 0.055 & 0.005 & 0.003 & 0.005 & 0.009 & 0.003 \\
\hline \multirow[t]{2}{*}{ Tradable } & -0.001 & $0.030^{* * *}$ & $-0.006^{* * *}$ & $-0.007 * * *$ & $-0.030 * * *$ & $-0.026^{* * *}$ & $-0.005^{* * *}$ \\
\hline & 0.003 & 0.007 & 0.002 & 0.002 & 0.004 & 0.005 & 0.002 \\
\hline \multirow{2}{*}{$\overline{\text { Regulação }}$} & $0.032^{* * *}$ & 0.013 & 0.003 & -0.0006 & $0.011^{* * *}$ & $-0.030^{* * *}$ & $-0.035^{* * *}$ \\
\hline & 0.005 & 0.016 & 0.003 & 0.003 & 0.005 & 0.007 & 0.002 \\
\hline \multirow[t]{2}{*}{ Reestruturação } & 0.028 & -0.070 & 0.010 & 0.0007 & 0.005 & $-0.041^{* * *}$ & $0.032 * * *$ \\
\hline & 0.039 & 0.105 & 0.010 & 0.004 & 0.004 & 0.010 & 0.006 \\
\hline \multirow[t]{2}{*}{ Minoritário } & 0.016 & -0.066 & $0.040^{* * *}$ & 0.007 & $0.026^{* *}$ & $0.065^{* * *}$ & $0.008^{*}$ \\
\hline & 0.018 & 0.097 & 0.011 & 0.007 & 0.011 & 0.012 & 0.005 \\
\hline \multirow[t]{2}{*}{ Listada } & $0.057^{*}$ & -0.063 & $0.067^{* * *}$ & $0.018^{* * *}$ & $0.029^{* * *}$ & $0.035^{* * *}$ & $-0.016^{* * *}$ \\
\hline & 0.034 & 0.065 & 0.014 & 0.003 & 0.005 & 0.013 & 0.006 \\
\hline \multirow{2}{*}{$\begin{array}{l}\text { Grupo de } \\
\text { controle }\end{array}$} & $1.287^{* * *}$ & $1.070^{* * *}$ & $0.425^{* * *}$ & $0.751^{* * *}$ & $0.710^{* * *}$ & $0.520^{* * *}$ & $0.770^{* * *}$ \\
\hline & 0.053 & 0.041 & 0.040 & 0.040 & 0.037 & 0.037 & 0.061 \\
\hline Variável & $0.195^{* * *}$ & $0.080 * * *$ & $0.556^{* * *}$ & $0.035^{* * *}$ & $0.172^{* * *}$ & $0.831^{* * *}$ & $0.555^{* * *}$ \\
\hline defasada & 0.019 & 0.020 & 0.015 & 0.005 & 0.016 & 0.007 & 0.017 \\
\hline \multirow[t]{2}{*}{ Constante } & $-0.137^{* * *}$ & -0.015 & $-0.062^{* * *}$ & $-0.022^{* * *}$ & $-0.070^{* * *}$ & $-0.210^{* * *}$ & $-0.022^{*}$ \\
\hline & 0.034 & 0.052 & 0.015 & 0.004 & 0.008 & 0.019 & 0.014 \\
\hline Observações & 1798 & 2158 & 1960 & 2257 & 1903 & 2044 & 1580 \\
\hline Pseudo $\mathrm{R}^{2}$ & .332 & 0.352 & 0.441 & 0.397 & 0.468 & 0.554 & 0.561 \\
\hline Teste de Sargan ${ }^{\S}$ & 0.000 & 0.000 & 0.001 & 0.002 & 0.000 & 0.000 & 0.005 \\
\hline
\end{tabular}

$\left(\right.$ Prob $\left.>\chi^{2}\right)$

* Significante em $10 \%$.

** Significante em $5 \%$.

$* * *$ Significante em $1 \%$

$\S$ Teste de Sargan para sobre-identificação de restrições. A não rejeição da hipótese nula indica a validade dos instrumentos utilizados. 
Tabela 7

Efeitos da privatização sobre o desempenho das empresas privatizadas

Análise econômica em painel

Critérios: Investimento, Produção, Estrutura Financeira e Impostos

Teste empírico do modelo $I P_{i t}=\alpha+\varphi I P_{i(t-1)}+\gamma$ PRIVATIZAÇÃO $+\beta X_{i t}+\delta M L_{t}+e_{i t}$ onde: $I P_{i t}$ é um indicador de performance e $I P_{i(t-1)}$ é o valor do indicador defasado em um período. O efeito da privatização é captado pela variável PRIVATIZAÇÃO. $X_{i t}$ é um vetor $(T x N)$ que contém as variáveis de controle(TRADABLE, REGULAÇÃO,

REESTRUTURAÇÃO, MINORITÁRIO, CÂMBIO e LISTADA). A variável $M L_{t}$, é a média observada no ano $t$ para um grupo de empresas listadas que formam o grupo de controle. Os estimadores foram obtidos pelo método de Arellano e Bond (1991), implementado pelo pacote econométrico Stata.

\begin{tabular}{|c|c|c|c|c|c|c|c|}
\hline \multirow[b]{2}{*}{ Variável } & \multicolumn{3}{|c|}{ Investimento } & \multirow{2}{*}{$\begin{array}{c}\text { Produto } \\
\text { Log } \\
\text { RL }\end{array}$} & \multicolumn{2}{|c|}{ Financeiro } & \multirow{2}{*}{$\begin{array}{c}\text { Impostos } \\
\text { IL/RL }\end{array}$} \\
\hline & $\begin{array}{c}\text { Log } \\
\text { IMOB }\end{array}$ & $\mathrm{I} / \mathrm{RL}$ & I/IMOB & & LCOR & $\mathrm{DLP} / \mathrm{PL}$ & \\
\hline \multirow[t]{2}{*}{ Privatização } & $0.012^{* * *}$ & -0.032 & $0.057^{* * *}$ & $0.008^{* *}$ & $0.140^{* * *}$ & $-0.029^{*}$ & $-0.006^{* * *}$ \\
\hline & 0.004 & 0.009 & 0.010 & 0.004 & 0.015 & 0.020 & 0.001 \\
\hline \multirow[t]{2}{*}{ Tradable } & $-0.005^{*}$ & 0.003 & $-0.034^{* * *}$ & $-0.010^{* * *}$ & 0.019 & $-0.028^{* * *}$ & $-0.006^{* * *}$ \\
\hline & 0.002 & 0.005 & 0.007 & 0.003 & 0.017 & 0.010 & 0.005 \\
\hline \multirow[t]{2}{*}{ Regulação } & $0.027^{* * *}$ & 0.003 & $-0.034^{* * *}$ & $-0.010^{* * *}$ & 0.019 & $-0.028^{* * *}$ & $0.006^{* * *}$ \\
\hline & 0.003 & 0.007 & 0.009 & 0.003 & 0.019 & 0.017 & 0.001 \\
\hline \multirow[t]{2}{*}{ Reestruturação } & $0.018^{* * *}$ & $0.055^{* * *}$ & $-0.066^{* * *}$ & 0.004 & $-0.102^{* * *}$ & $-0.235^{* * *}$ & $-0.004^{* *}$ \\
\hline & 0.005 & 0.020 & 0.012 & 0.004 & 0.022 & 0.022 & 0.001 \\
\hline \multirow[t]{2}{*}{ Minoritário } & -0.011 & -0.021 & $0.065^{* * *}$ & $-0.016^{* * *}$ & $0.348^{* * *}$ & $-0.137^{* * *}$ & $0.023^{* * *}$ \\
\hline & 0.009 & 0.022 & 0.022 & 0.005 & 0.062 & 0.041 & 0.005 \\
\hline \multirow[t]{2}{*}{ Listada } & $0.008^{*}$ & $0.122^{* * *}$ & $0.115^{* * *}$ & $0.007^{* * *}$ & 0.016 & $0.085^{* * *}$ & $-0.004^{* * *}$ \\
\hline & 0.004 & 0.020 & 0.011 & 0.003 & 0.016 & 0.024 & 0.001 \\
\hline \multirow{2}{*}{$\begin{array}{l}\text { Grupo de } \\
\text { controle }\end{array}$} & $0.101^{* * *}$ & $0.954^{* * *}$ & $0.970^{* * *}$ & $0.115^{* * *}$ & $0.635^{* * *}$ & $0.887^{* * *}$ & $1.070^{* * *}$ \\
\hline & 0.008 & 0.032 & 0.024 & 0.008 & 0.055 & 0.030 & 0.067 \\
\hline \multirow{2}{*}{$\begin{array}{l}\text { Variável } \\
\text { defasada }\end{array}$} & $0.912^{* * *}$ & $0.304^{* * *}$ & $0.075^{* * *}$ & $0.926^{* * *}$ & $0.458^{* * *}$ & $0.186^{* * *}$ & $0.040^{* * *}$ \\
\hline & 0.004 & 0.012 & 0.013 & 0.006 & 0.013 & 0.014 & 0.011 \\
\hline \multirow[t]{2}{*}{ Câmbio } & $-0.20^{* *}$ & & & $-0.012^{* *}$ & & & \\
\hline & 0.003 & & & 0.004 & & & \\
\hline \multirow[t]{2}{*}{ Constante } & 0.029 & $-0.120^{* * *}$ & $-0.164^{* * *}$ & $-0.220^{* * *}$ & $-0.299^{* * *}$ & -0.122 & 0.004 \\
\hline & 0.043 & 0.024 & 0.0186 & 0.050 & 0.080 & 0.032 & 0.003 \\
\hline Observações & 2561 & 1702 & 2185 & 2073 & 2120 & 2256 & 1598 \\
\hline Pseudo $\mathrm{R}^{2}$ & 0.373 & 0.491 & 0.538 & 0.725 & 0.584 & 0.610 & 0.447 \\
\hline $\begin{array}{l}\text { Teste de } \text { Sargan }^{\S} \\
\left(\text { Prob }>\chi^{2}\right)\end{array}$ & 0.000 & 0.010 & 0.004 & 0.000 & 0.000 & 0.000 & 0.012 \\
\hline
\end{tabular}

* Significante em $10 \%$.

** Significante em $5 \%$.

*** Significante em $1 \%$.

$\S$ Teste de Sargan para sobre-identificação de restrições. A não rejeição da hipótese nula indica a validade dos instrumentos utilizados. 


\section{Conclusão}

Este artigo enfocou as mudanças no desempenho das companhias que foram privatizadas no Brasil desde 1991. Em termos de cobertura é o mais abrangente já realizado. Todas as companhias com informações disponíveis foram incluídas na análise. Além dos tradicionais testes de média e mediana, também conduzimos uma análise de regressão com dados em painel que permitiu filtrar os efeitos de importantes fatores como flutuações macroeconômicas, regulação, listagem em bolsa, atuação em setores tradable, participação minoritária do governo no bloco de controle e reestruturação anterior à privatização.

Os resultados obtidos indicam que estas empresas tornaram-se mais eficientes após a privatização. Em particular observou-se um aumento da lucratividade e da eficiência operacional. Aparentemente, a perda do suporte financeiro do Estado tem um grande impacto sobre a estrutura financeira das empresas, pois se observou um aumento da liquidez corrente e uma redução do endividamento de longo prazo. Os efeitos da privatização sobre investimento, nível de produção, pagamento de dividendos e recolhimento de impostos são menos claros.

Observamos também que do ponto de vista analítico, os testes de médias e as regressões com dados em painel apresentam resultados distintos, destacando a importância dos controles introduzidos no segundo procedimento de estimação dos determinantes do desempenho econômico-financeiro das empresas privatizadas.

Com relação à pesquisa futura, é particularmente necessário promover o esclarecimento dos custos e de outros benefícios da privatização. Esta pesquisa é extremamente relevante, uma vez que o tema privatização envolve forte apelo emocional, sendo comumente permeado por dogmas e nacionalismos exacerbados. O surgimento de novas evidências pode contribuir para trazer essa discussão a um nível mais objetivo.

\section{Referências}

Anuatti-Neto, F., Barossi-Filho, M., Carvalho, A. G., \& Macedo, R. (2003). Costs and benefits of privatization: Evidence from Brazil. Research Network Working Paper No. 455, IADB, Washington, DC.

Arellano, M. \& Bond, S. (1991). Some test of specification for panel data: Monte Carlo evidence and an application to employment equations. Review of Economic Studies, 58:277-297.

BNDES (1999a). Privatizações No Brasil - 1991/99. BNDES, Rio de Janeiro. 
BNDES (1999b). Sistema de Informações. BNDES, Rio de Janeiro.

BNDES (2001). Privatização. Disponível em www.bndes.gov.br.

La Porta, R. \& López-de Silanes, F. (1999). The benefits of privatization: Evidence from Mexico. Quartely Journal of Economics, pages 1193-1242.

Macedo, R. (1985). Os Salários Nas Empresas Estatais. Nobel, São Paulo.

Megginson, W. L. \& Netter, J. M. (2001). From state to market: A survey of empirical studies of privatization. Journal of Economic Literature, 39:321-389.

Pinheiro, A. C. (1996). Impactos microeconômicos da privatização no Brasil. Pesquisa e Planejamento Econô mico, 26(3):357-98.

Pinheiro, A. C. (2000). Após a privatização. Rio de Janeiro: BNDES. Disponível em www.bndes.gov.br.

Pinheiro, A. C. \& Giambiagi, F. (1997). Lucratividade, dividendos e investimentos das empresas estatais: Uma contribuição para o debate sobre privatização no Brasil. Revista Brasileira de Economia, 51:93-131. 


\section{Apêndice A}

\section{Descrição da Amostra}

Com a finalidade de descrever o programa de privatização de forma mais apropriada, detalhamos a seguir quais empresas o governo possuía antes do programa e quais foram privatizadas. Como não obtivemos informações precisas sobre a situação inicial nos vários governos estaduais, a descrição sobre o que o governo possuía antes do programa de privatização está restrita ao âmbito federal, o segmento mais importante do programa. Quanto ao que foi privatizado, as informações abrangem todo o programa, exceto as novas concessões de serviços públicos.

Em 1980, o governo federal realizou um levantamento de todas as suas "entidades", incluindo companhias, fundações, administrações portuárias, institutos de pesquisa e conselhos responsáveis pelo registro profissional. Na ocasião, essas instituições somavam 560, entre as quais 250 eram organizadas como empresas, principalmente na forma de sociedades anônimas. Nos anos 80, ocorreram algumas privatizações menores e também algumas poucas empresas foram fechadas. Além disso, no início do programa, em 1991, outras não mais existiam. Em conseqüência, o programa começou com 186 firmas ainda sob o controle do governo. Ao final de 2000, principalmente devido ao programa de privatização, esse número foi reduzido para 102 .

A tabela A.1 lista as companhias privatizadas pelo governo federal desde 1990. A tabela A.2 lista as firmas privatizadas em nome de alguns estados, pelo BNDES, ao lado de algumas EEs do governo federal e firmas privatizadas pelo estado de São Paulo. Em ambas tabelas, destacamos as empresas incluídas na amostra usada neste artigo e à receita obtida, em cada caso, com as privatizações. Para uso posterior na análise, uma referência é feita também às companhias que estavam listadas na Bolsa de Valores de São Paulo antes da privatização. 
Tabela A.1

Empresas federais e estaduais privatizadas entre 1990 e 2000

\begin{tabular}{|c|c|c|c|c|c|}
\hline Leilão & $\begin{array}{c}\text { Nome da } \\
\text { companhia }\end{array}$ & $\begin{array}{l}\text { Data do } \\
\text { leilão }\end{array}$ & $\begin{array}{c}\text { Receita do } \\
\left(\text { US\$ Milhão) }{ }^{1}\right.\end{array}$ & $\begin{array}{l}\text { Parte da } \\
\text { amostra }\end{array}$ & Listada \\
\hline \multirow{2}{*}{ USIMINAS } & Usinas Sid. de Minas Gerais (Usiminas) & $24 / 10 / 1991$ & 2.310 & 1 & 1 \\
\hline & Usiminas Mecânica (Usimec) & & & 0 & 0 \\
\hline CELMA & Cia. Eletromecânica & $1 / 11 / 1991$ & 96 & 0 & 0 \\
\hline MAFERSA & Mafersa S.A. & $11 / 11 / 1991$ & 50 & 0 & 0 \\
\hline \multirow[t]{2}{*}{ COSINOR } & Cia. Siderúrgica do Nordeste (Cosinor) & $14 / 11 / 1991$ & 15 & 0 & 0 \\
\hline & Cosinor Distribuidora (Cosinor Dist.)* & & & 0 & 0 \\
\hline SNBP & Serviço de Navegação da Bacia do Prata & $14 / 1 / 1992$ & 12 & 0 & 0 \\
\hline INDAG & Indag Fertilizantes & $23 / 1 / 1992$ & 7 & 0 & 0 \\
\hline $\mathrm{AFP}$ & Aços Finos Piratini & $14 / 2 / 1992$ & 109 & 1 & 0 \\
\hline PETROFLEX & Petroflex Indústra e Comércio S.A & $10 / 4 / 1992$ & 255 & 1 & 1 \\
\hline COPESUL & Cia. Petroquímica do Sul & $15 / 5 / 1992$ & 871 & 1 & 1 \\
\hline \multirow[t]{2}{*}{ CAN } & Cia. Nacional de Álcalis & $15 / 7 / 1992$ & 87 & 0 & 0 \\
\hline & Álcalis Rio Grande do Norte (Alcanorte)* & & & 0 & 0 \\
\hline \multirow[t]{2}{*}{$\mathrm{CST}$} & Cia. Siderúrgica de Tubarão & 16 e $23 / 07 / 92$ & & & \\
\hline & & & 837 & 1 & 1 \\
\hline NITRIFLEX & Nitriflex & $6 / 8 / 1992$ & 35 & 1 & 0 \\
\hline FOSFÉRTIL & Fertilizantes Fosfatados S.A. & $12 / 8 / 1992$ & 226 & 1 & 1 \\
\hline POLISUL & Polisul & $11 / 9 / 1992$ & 188 & 0 & 0 \\
\hline $\mathrm{PPH}$ & $\mathrm{PPH}$ & $29 / 9 / 1992$ & 94 & 0 & 0 \\
\hline GOIASFÉRTIL & Goiás Fertilizantes S.A & $8 / 10 / 1992$ & 22 & 0 & 0 \\
\hline \multirow[t]{3}{*}{ ACESITA } & Cia. Aços Especiais Itabira & & & 1 & 1 \\
\hline & Acesita & $23 / 10 / 1992$ & 697 & 0 & 0 \\
\hline & Forjas Acesita (Fasa)* & & & 0 & 0 \\
\hline \multirow[t]{2}{*}{$\mathrm{CBE}$} & Cia. Brasileira de Estireno & $3 / 12 / 1992$ & 11 & 1 & 0 \\
\hline & *Poliolefinas & $19 / 3 / 1993$ & 87 & 0 & 0 \\
\hline \multirow[t]{2}{*}{$\mathrm{CSN}$} & Cia. Siderúrgica Nacional & $2 / 4 / 1993$ & 2.028 & 1 & 1 \\
\hline & Fábrica de Estruturas Metálicas S.A.* & & & 0 & 0 \\
\hline \multirow[t]{2}{*}{ ULTRAFÉRTIL } & $\begin{array}{l}\text { Ultrafértil S.A. Indústria e Comércio de Fertili- } \\
\text { zantes }\end{array}$ & & & 1 & 0 \\
\hline & & $24 / 6 / 1993$ & 226 & & \\
\hline COSIPA & Cia. Siderúrgica Paulisa & $20 / 8 / 1993$ & 1.470 & 1 & 1 \\
\hline AÇOMINAS & Aços Minas Gerais S.A. & $10 / 9 / 1993$ & 721 & 1 & 0 \\
\hline OXITENO & Oxiteno & $15 / 9 / 1993$ & 56 & 1 & 1 \\
\hline PQU & Petroquímica União S.A. & $25 / 1 / 1994$ & 328 & 1 & 1 \\
\hline ARAFÉRTIL & Arafértil Fertilizantes - ARAFÉRTIL & $15 / 7 / 1994$ & 13 & 0 & 0 \\
\hline CARAÍBA & Mineração Caraíba LTDA. & $28 / 7 / 1994$ & 6 & 1 & 0 \\
\hline ACRINOR & Acrinor & $12 / 8 / 1994$ & 13 & 0 & 0 \\
\hline COPERBO & Coperbo & $16 / 8 / 1994$ & 32 & 0 & 0 \\
\hline CIQUINE & Ciquine & $17 / 8 / 1994$ & 30 & 1 & 1 \\
\hline POLIALDEN & Polialden & $17 / 8 / 1994$ & 19 & 1 & 1 \\
\hline POLITERO & Politero & $18 / 8 / 1994$ & 73 & 1 & 1 \\
\hline \multirow[t]{4}{*}{ EMBRAER } & Empresa Bras. de Aeronáutica (Embraer) & $7 / 12 / 1994$ & 455 & 1 & 1 \\
\hline & Embrear Aircraft Corporation (EAC)* & & & 0 & 0 \\
\hline & Embraer Aviation International (EAI)* & & & 0 & 0 \\
\hline & Indústria Aeronáutica Neiva (Neiva)* & & & 0 & 0 \\
\hline ESCELSA & Espírito Santo Centrais Elétricas S.A. & $11 / 7 / 1995$ & 522 & 1 & 1 \\
\hline COPENE & Cia. Petroquímica do Nordeste & $15 / 8 / 1995$ & 745 & 1 & 1 \\
\hline $\mathrm{CPC}$ & $\mathrm{CPC}$ & $29 / 9 / 1995$ & 161 & 0 & 0 \\
\hline CQR & CQR & $5 / 10 / 1995$ & 2 & 1 & 0 \\
\hline SALGEMA & SALGEMA & $5 / 10 / 1995$ & 183 & 0 & 0 \\
\hline NITROCARB. & Nitrocarbono & $5 / 12 / 1995$ & 37 & 1 & 1 \\
\hline
\end{tabular}




\begin{tabular}{|c|c|c|c|c|c|}
\hline Leilão & $\begin{array}{c}\text { Nome da } \\
\text { companhia }\end{array}$ & $\begin{array}{c}\text { Data do } \\
\text { leilão }\end{array}$ & $\begin{array}{c}\text { Receita do } \\
\left(\text { US\$ Milhão) }{ }^{1}\right.\end{array}$ & $\begin{array}{l}\text { Parte da } \\
\text { amostra }\end{array}$ & Listada \\
\hline PRONOR & Pronor & $5 / 12 / 1995$ & 99 & 1 & 1 \\
\hline POLIPROP. & Polipropileno & $1 / 2 / 1996$ & 86 & 1 & 1 \\
\hline LIGHT & Light Serviços de Eletricidade S.A. & $21 / 5 / 1996$ & 3.094 & 1 & 1 \\
\hline DETEN & Deten & $22 / 5 / 1996$ & 12 & 1 & 0 \\
\hline CVRD & Cia. Vale do Rio Doce & $6 / 5 / 1997$ & 6.858 & 1 & 1 \\
\hline CODESP & Terminal de Contêiners Tecon 1 (Codesp) & $17 / 9 / 1997$ & 251 & 0 & 0 \\
\hline CDRJ & CDRJ - Porto de Angra dos Reis & $5 / 11 / 1998$ & 8 & 0 & 0 \\
\hline CDRJ & CDRJ-Term. de Cont. 1 (Porto de Sepetiba) & $3 / 9 / 1998$ & 79 & 0 & 0 \\
\hline CDRJ & CDRJ-Term. Roll-on Roll-off (Porto do Rio) & $3 / 11 / 1998$ & 26 & 0 & 0 \\
\hline RFF & Rede Ferroviária Federal S.A. (Oeste) & $5 / 3 / 1996$ & 63 & 0 & 0 \\
\hline RFF & Rede Ferroviária Federal S.A. (SP) & $10 / 11 / 1998$ & 206 & 1 & 0 \\
\hline RFF & Rede Ferroviária Federal S.A. (Sudeste) & $20 / 9 / 1996$ & 870 & 1 & 0 \\
\hline RFF & Rede Ferroviária Federal S.A. (Sul) & $13 / 12 / 1996$ & 209 & 0 & 0 \\
\hline RFF & Rede Ferrov. Fed. S.A. (Tereza Cristina) & $22 / 11 / 1996$ & 18 & 0 & 0 \\
\hline RFF & Rede Ferroviária Fed. S.A. (Centro-Leste) & $14 / 6 / 1996$ & 316 & 0 & 0 \\
\hline MERIDIONAL & Banco Meridional do Brasil S.A. & $4 / 12 / 1997$ & 240 & 0 & 0 \\
\hline EMBRATEL & Embratel & $29 / 7 / 1998$ & 2.276 & 1 & 1 \\
\hline TELESP & Telesp Operacional, Borda do Campo & $29 / 7 / 1998$ & 4.967 & 2 & 1 \\
\hline CENTRO SUL & $\begin{array}{l}\text { Telepar, Telebrasília, Telegoiás e outras } 4 \text { com- } \\
\text { panhias fechadas: CTMR, Telemat, Teleron, Te- } \\
\text { leacre }\end{array}$ & $29 / 7 / 1998$ & 1.778 & 3 & 3 \\
\hline SUDESTE CEL & & $29 / 7 / 1998$ & 1.168 & 1 & 0 \\
\hline TELEMIG CEL & & $29 / 7 / 1998$ & 649 & 1 & 0 \\
\hline CELULAR SUL & & $29 / 7 / 1998$ & 601 & 4 & 0 \\
\hline NORDESTE CEL & & $29 / 7 / 1998$ & 567 & 7 & 0 \\
\hline LESTE CEL & & $29 / 7 / 1998$ & 368 & 2 & 0 \\
\hline C. OESTE CEL & Telegoiás Celular e outras 5 companhias & $29 / 7 / 1998$ & 378 & 3 & 1 \\
\hline TELENORTE C & & $29 / 7 / 1998$ & 161 & 2 & 0 \\
\hline GERASUL & Centrais Geradoras do Sul do Brasil S.A. & $15 / 9 / 1998$ & 1.962 & 1 & 0 \\
\hline GUARARAPES & GUARARAPES & $7 / 12 / 1998$ & 0.1 & 1 & 1 \\
\hline DATAMEC & Datamec S.A. & $23 / 6 / 1999$ & 49 & 0 & 0 \\
\hline BANESPA & Banco do Estado de São Paulo & $20 / 11 / 2000$ & 3.604 & 0 & 0 \\
\hline \multirow[t]{2}{*}{ Petrobrás } & Petrobrás** & $0908 / 00$ & 4.032 & 1 & 1 \\
\hline & Total & & $56.841,20$ & 75 & 38 \\
\hline
\end{tabular}


Tabela A.2

Empresas dos estados, participações minoritárias do governo federal e programa de privatização do estado de São Paulo

\begin{tabular}{|c|c|c|c|c|}
\hline Nome da Companhia & $\begin{array}{l}\text { Data do } \\
\text { leilão }\end{array}$ & $\begin{array}{l}\text { Receita do leilão } \\
\text { (US\$ Milhão) }\end{array}$ & $\begin{array}{l}\text { Parte da } \\
\text { amostra }\end{array}$ & Listada \\
\hline Banco Banerj S.A. - BANERJ & $26 / 06 / 97$ & 289 & 0 & 0 \\
\hline Banco de Crédito de Minas Gerais S.A. - Credireal & $07 / 08 / 97$ & 112 & 0 & 0 \\
\hline Banco do Estado da Bahia - BANEB & $22 / 07 / 99$ & 147 & 0 & 0 \\
\hline Banco do Estado de Minas Gerais - BEMGE & $14 / 09 / 98$ & 494 & 0 & 0 \\
\hline Banco do Estado de Pernambuco S.A. & $17 / 11 / 98$ & 153 & 0 & 0 \\
\hline Banco do Estado de Santa Catarina - BESC & $30 / 09 / 97$ & 28 & 0 & 0 \\
\hline Centrais Elétricas Cachoeira Dourada & $05 / 09 / 97$ & 854 & 1 & 1 \\
\hline Centrais Elétricas do Pará S.A. - CELPA & $09 / 07 / 98$ & 504 & 0 & 0 \\
\hline CELPE & 2000 & 1135 & 1 & 1 \\
\hline Centrais Elétricas Matogrossenses S.A. - CEMAT & $27 / 11 / 97$ & 814 & 1 & 1 \\
\hline CESP Paranapanema & $28 / 07 / 99$ & 1.164 & 1 & 1 \\
\hline CESP TIETÊ & $01 / 11 / 99$ & 1.140 & 1 & 1 \\
\hline Cia. de Gás de São Paulo - COMGÁS & $14 / 04 / 99$ & 1.076 & 1 & 1 \\
\hline Cia. União de Seguros Gerais & $20 / 11 / 97$ & 45 & 0 & 0 \\
\hline $\begin{array}{l}\text { Cia. Centro Oeste de Dist. de Energia Elétrica - } \\
\text { (AES-SUL) }\end{array}$ & $21 / 10 / 97$ & 1.436 & 1 & 1 \\
\hline Cia. de Eletricidade de Minas Gerais-CEMIG* & $28 / 05 / 97$ & 1.053 & 1 & 1 \\
\hline Cia. de Eletricidade do Estado da Bahia-COELBA & $31 / 07 / 97$ & 1.965 & 1 & 1 \\
\hline Cia. de Eletricidade do Rio de Janeiro_CERJ & $20 / 11 / 96$ & 951 & 1 & 1 \\
\hline Cia. de Navegação do Rio de Janeiro-CONERJ & $05 / 02 / 98$ & 29 & 0 & 0 \\
\hline Cia. de Saneamento Básico de São Paulo-SABESP* & $31 / 07 / 97$ & 375 & 1 & 1 \\
\hline Cia. de Saneamento Básico do Paraná-SANEPAR* & $08 / 06 / 98$ & 217 & 1 & 1 \\
\hline Cia. Energética de Brasília-CEB* & $30 / 04 / 97$ & 74 & 1 & 1 \\
\hline Cia. Energética do Ceará-COELCE & $02 / 04 / 98$ & 1.338 & 1 & 1 \\
\hline Cia. Estadual de Gás do Rio de Janeiro-CEG & $14 / 07 / 97$ & 430 & 1 & 0 \\
\hline Cia. Fluminense de Trens Urbanos & $15 / 07 / 98$ & 240 & 0 & 0 \\
\hline Cia. Metropolitano do Rio de Janeiro* & $19 / 12 / 97$ & 262 & 0 & 0 \\
\hline $\begin{array}{l}\text { Cia. N. NE. De Dist. De Energia Elétrica-CEEE - } \\
\text { (RGE) }\end{array}$ & $21 / 10 / 97$ & 1.635 & 1 & 1 \\
\hline Cia. Paranaense de Energia - COPEL* & $20 / 09 / 96$ & 413 & 1 & 1 \\
\hline Cia. Paulista de Força e Luz-CPFL & $05 / 11 / 97$ & 2.833 & 1 & 1 \\
\hline Cia. Riograndense de Telecomunicações-CRT & $19 / 06 / 98$ & 2.496 & 1 & 1 \\
\hline COSERN & $12 / 12 / 97$ & 718 & 1 & 0 \\
\hline EBE-BANDEIRANTE DE ENERGIA & $17 / 09 / 98$ & 1.235 & 1 & 0 \\
\hline Elektro Eletricidade e Serviços S.A. - ELEKTRO & $16 / 07 / 98$ & 1.917 & 1 & 0 \\
\hline Eletricidade de São Paulo S.A. - Metropolitana & $15 / 04 / 98$ & 3.445 & 1 & 0 \\
\hline $\begin{array}{l}\text { Empresa Energética de Mato Grosso do Sul - ENER- } \\
\text { SUL }\end{array}$ & $19 / 11 / 97$ & 783.0 & 1 & 0 \\
\hline Empresa Energética de Sergipe - ENERGIPE & $03 / 12 / 97$ & 560 & 0 & 0 \\
\hline Estrada de Ferro Paraná Oeste S.A.-Ferroeste & $10 / 12 / 96$ & 25 & 0 & 0 \\
\hline Riogás S.A. & $14 / 07 / 97$ & 146 & 0 & 0 \\
\hline Terminal Garagem Menezes Côrtes & $28 / 10 / 98$ & 67 & 0 & 0 \\
\hline Total & & 32.598 & 27 & 18 \\
\hline
\end{tabular}

1 Inclui dívida transferida.

** Participações minoritárias nas EEs restantes.

Fonte: BNDES. 


\section{Apêndice B}

\section{Testes de Média e Mediana}

No caso brasileiro, as privatizações individuais estão distribuídas ao longo de vários anos, logo os testes de média e mediana têm por referencial a comparação da média dos dois anos imediatamente anteriores à privatização com a média dos dois anos imediatamente posteriores a ela.

Considerando $P_{i}$ como o ano da privatização de cada antiga $E E$ E em nosso exemplo. Considerando $X_{i}^{t-j}$ como o indicador do valor calculado por $j$ anos antes da privatização de cada companhia $i$. Considerando também $X_{i}^{t+j}$ o indicador do valor calculado para $j$ anos depois da privatização de cada companhia $i$. Finalmente, considerando $M_{i}^{A}$ e $M_{i}^{D}$ como os valores médios dos indicadores para períodos de dois anos antes e depois para cada firma $i$. Assim, temos os seguintes arranjos de variáveis

$$
\begin{gathered}
X_{1}^{t-1}, X_{1}^{t-2}, M_{1}^{A}, P_{1}, M_{1}^{D}, X_{1}^{t+1}, X_{1}^{t+2} \\
X_{2}^{t-2}, X_{2}^{t-1}, M_{2}^{A}, P_{2}, M_{2}^{D}, X_{2}^{t+1}, X_{2}^{t+2} \\
\ldots \ldots \ldots \ldots \cdots \cdots \cdots \cdots \\
\quad \cdots \cdots \cdots \cdots \\
X_{n}^{t-2}, X_{n}^{t-1}, M_{n}^{A}, P_{n}, M_{n}^{D}, X_{n}^{t+1}, X_{n}^{t+2}
\end{gathered}
$$

em que $M_{i}^{A}=\sum X_{i}^{t-j}$ e $M_{i}^{D}=\sum X_{i}^{t+j}$. O valor médio/mediano geral para os indicadores financeiros anteriores e posteriores à privatização são dados, respectivamente, por $M^{A}$ e $M^{D}$ (os valores médio/mediano de $M_{i}^{A}$ e $M_{i}^{D}$ ao longo de i).

Neste método, um indicador particular para uma firma particular está incluído no teste somente se houver dados disponíveis para os quatro anos como descrito.

\section{Ajustamento para Efeitos Macroeconômicos}

A fim de filtrar as flutuações macroeconômicas, usamos um procedimento similar àquele adotado em La Porta e López-de Silanes (1999). Começamos calculando os mesmos indicadores $X_{i}^{t}$ como descrito anteriormente. Então, calculamos os mesmos indicadores para cada companhia em nosso grupo de controle. Em seguida, calculamos a média através da firmas no grupo de controle para cada ano, $M E P^{j}$, onde $j$ é o ano. O grupo de controle inclui companhias públicas controladas pelo setor privado para as quais os dados estavam disponíveis ao longo de todo o período. 
Então, tomamos as diferenças entre os indicadores das empresas privatizadas e os indicadores obtidos das firmas privadas. Assim, o arranjo das variáveis torna-se:

$$
\begin{aligned}
& \left(X_{1}^{t-2}-M E P^{t-2}\right),\left(X_{1}^{t-1}-M E P^{t-1}\right), M_{1}^{A *}, P_{1}, M_{1}^{D *},\left(X_{1}^{t+1}-M E P^{t+1}\right), \\
& \left(X_{1}^{t+2}-M E P^{t+2}\right)\left(X_{2}^{t-2}-M E P^{t-2}\right),\left(X_{2}^{t-1}-M E P^{t-10}\right), M_{2}^{A *}, P_{2}, M_{2}^{D *} \\
& \left(X_{2}^{t+1}-M E P^{t+1}\right),\left(X_{2}^{t+2}-M E P^{t+2}\right) \ldots \cdots \cdots \cdots \cdots \cdots \cdots \cdots \\
& \left(X_{n}^{t-2}-M E P^{t-2}\right),\left(X_{n}^{t-1}-M E P^{t-1}\right), M_{n}^{A *}, P_{n}, M_{n}^{D *},\left(X_{n}^{t+1}-M E P^{t+1}\right), \\
& \left(X_{n}^{t+2}-M E P^{t+2}\right)
\end{aligned}
$$

